\title{
Inhibition of breast cancer cell invasion by melatonin is mediated through regulation of the p38 mitogen-activated protein kinase signaling pathway
}

\author{
Lulu Mao ${ }^{1,2}$, Lin Yuan ${ }^{1}$, Lauren M Slakey ${ }^{1}$, Frank E Jones ${ }^{3}$, Matthew E Burow ${ }^{2,4}$, Steven M Hill ${ }^{1,2^{*}}$
}

\begin{abstract}
Introduction: The pineal gland hormone, melatonin, has been shown by numerous studies to inhibit the proliferation of estrogen receptor $\alpha(E R \alpha)$-positive breast cancer cell lines. Here, we investigated the role of melatonin in the regulation of breast cancer cell invasion.

Methods: Three invasive MCF-7 breast cancer cell clones - MCF-7/6, MCF-7/Her2.1, and MCF-7/CXCR4 cells - were employed in these studies. All three cell lines exhibited elevated phosphorylation of the ERK1/2 and p38 mitogenactivated protein kinase (MAPK) as determined by Western blot analysis. The effect of melatonin on the invasive potential of these human breast cancer cells was examined by matrigel invasion chamber assays. The expression and proteinase activity of two matrix metalloproteinases (MMPs), MMP-2 and MMP-9, were analyzed by Western blot analysis and gelatin zymography, respectively.

Results: Melatonin $\left(10^{-9} \mathrm{M}\right)$ significantly suppressed the invasive potential of MCF-7/6 and MCF-7/Her2.1 cells as measured by matrigel invasion chamber assays, and significantly repressed the proteinase activity of MMP-2 and MMP-9. In MCF-7/CXCR4 cells, melatonin significantly inhibited stromal-derived factor-1 (SDF-1/CXCL12) induced cell invasion and activity of MMP-9. Elevated expression of the MT1 melatonin receptor further enhanced, while luzindole, an MT1/MT2 antagonist, abrogated melatonin's anti-invasive effect, suggesting that melatonin's effect on invasion is mediated, principally, through the MT1 receptor. Furthermore, melatonin repressed the phosphorylation of p38 MAPK in MCF-7/Her2.1 cells and blocked stromal-derived factor-1 (SDF-1) induced p38 phosphorylation in MCF-7/CXCR4 cells. SB230580, a p38 inhibitor, was able to mimic, while transfection of the cells with a constitutively-active MKK6b construct blocked melatonin's effect on cell invasion, suggesting that the anti-invasive action of melatonin is mediated through the p38 pathway.
\end{abstract}

Conclusions: Melatonin exerts an inhibitory effect on breast cancer cell invasion through down-regulation of the p38 pathway, and inhibition of MMP-2 and MMP-9 expression and activity.

\section{Introduction}

Over the last several decades, melatonin's growth-inhibitory action in breast cancer has been studied extensively both in vivo and in vitro. In contrast, only a minimal amount of work has been done with regard to the role of melatonin in breast cancer invasion and metastasis. It

\footnotetext{
* Correspondence: smhill@tulane.edu

'Department of Structural and Cellular Biology, Tulane University School of Medicine, 1430 Tulane Avenue, New Orleans, LA 70112, USA

Full list of author information is available at the end of the article
}

has been observed in several early correlative studies that the plasma level of melatonin is significantly reduced in cancer patients with metastatic disease as compared with those without metastases [1,2]. In 1998, Cos and colleagues [3] reported that physiological concentrations of melatonin $\left(10^{-9} \mathrm{M}\right)$ significantly reduced the invasive capacity of MCF-7 human breast cancer cells as measured by Falcon invasion chamber assays, a modified Boyden chamber assay, and that melatonin could enhance the expression of the adhesion proteins,

\section{C) Biomed Central}


E-cadherin and $\beta_{1}$ integrin. In addition, melatonin administration has been shown to reduce the incidence of metastases in several in vivo studies [4-6].

Collectively, these results suggest that melatonin may exert an inhibitory influence on breast cancer cell invasion and metastasis, possibly by decreasing cell attachment to the basement membrane. However, there has been no further exploration of melatonin's anti-invasive action and mechanism(s) since the work by Cos and colleagues in 1998. A major obstacle to a better understanding of melatonin's role in breast cancer invasion and metastasis is the lack of a cell line that exhibits a strong invasive potential but that is also estrogen receptor-alpha $(\mathrm{ER} \alpha)$-positive and melatonin-responsive. The ER $\alpha$-positive MCF-7 cell, which has been well characterized and extensively used in the in vitro studies examining melatonin's anti-proliferative effect and which has been shown to be responsive to melatoninmediated growth inhibition, is widely regarded as poorly invasive. Thus, the standard MCF-7 breast tumor cell line is not a good model for invasion/metastasis studies. Unfortunately, the highly invasive ER $\alpha$-negative MDAMB-231 cells are unresponsive to melatonin's growthinhibitory actions and thus are not a reasonable model to study melatonin's actions on invasion. Therefore, an alternative cell line that exhibits high invasive potential but that still retains the melatonin responsiveness is essential for a model system in which to study melatonin's actions on breast cancer invasion.

Here, we have used three invasive breast cancer cell lines. The MCF-7/6 cells were derived from parental MCF-7 cells by selection for metastatic potential by serial passaging in nude mice [7]. As compared with the MCF-7/AZ line (a parental MCF-7 cell clone renamed by the group of Marc Mareel, Gent University Hospital, Gent, Belgium), MCF-7/6 cells are invasive in the chick heart embryo invasion assay [7] and spontaneously metastasize in nude mice after subcutaneous injection [8]. These cells have been demonstrated to be ER $\alpha$ positive and progesterone receptor (PR)-positive.

A second cell line used in our studies is the MCF-7/ Her2.1 cell line, which has been stably transfected with and overexpresses the wild-type human Her2/neu (CerbB2) receptor. According to previous studies, receptor tyrosine kinase Her2/neu plays an important role in the malignant progression of breast cancer [9]. Amplification and overexpression of Her2/neu occur in approximately $15 \%$ to $30 \%$ of primary breast tumors and correlate with the nodal metastases and poor prognosis [10]. It was previously shown that Her2/neu overexpression in breast cancer cells frequently leads to hyperactivation of mitogen-activated protein kinase (MAPK) signaling pathways [11]. Moreover, overexpression of Her2/neu not only induces the invasive capacity in mammary epithelial cells but also promotes the invasiveness of breast cancer cells in vitro $[12,13]$ and induces metastasis in animal models $[13,14]$. Although the effect of Her2/neu on metastasis is well documented, the mechanism underlying the effect of Her2/neu on breast cancer invasion and metastasis is not fully understood. A recent study by Ke and colleagues [15] showed that, in human mammary epithelial cells, expression and activity of matrix metalloproteinase (MMP)-2 and MMP-9, two members of the MMP family which play an important role in the degradation of the extracellular matrix, were upregulated in response to overexpression of Her2/neu and that the regulation of MMP- 2 and MMP-9 by Her2/neu may be mediated through the p38 MAPK and PI3K (phosphoinositide 3-kinase) signaling pathways. These results suggest that the effects of Her2/ neu on breast cancer cell invasion may impinge on target molecules to orchestrate the degradation of the extracellular matrix through simultaneous activation of multiple signaling pathways.

Also used in our studies is an MCF-7 clone (MCF-7/ CXCR4) that overexpresses the chemokine receptor CXCR4, a recently described key regulator of breast cancer invasion and metastasis [16]. Through interaction with its cognate ligand, the chemokine stromal-derived factor-1 (SDF-1/CXCL12), CXCR4 is proposed to direct homing of breast cancer cells to particular sites of metastases [16]. It has been demonstrated that downregulation of CXCR4 inhibits in vitro invasiveness of breast cancer cell and blocks breast cancer metastasis in vivo $[17,18]$. Several lines of evidence suggest that the effect of the SDF-1/CXCR4 axis on cell invasion may involve activation of multiple signaling pathways, including the p38 MAPK pathway [19-21].

Although MCF-7/6, MCF-7/Her2.1, and MCF-7/ CXCR4 breast cancer cells acquire their malignant phenotypes through different mechanisms and approaches, their invasive potential may be enhanced through activation of a common intracellular signaling pathway that plays an essential role in regulating cancer cell invasion and metastasis. According to previous studies [22-25], the p38 MAPK is a central kinase in a common pathway that plays an important role in breast cancer invasion and metastasis by modulating the expression and activity of molecules involved in the degradation of extracellular matrix (that is, MMP-2 and MMP-9). Additionally, p38 MAPK has been reported to be activated by both the Her2/neu and SDF-1/CXCR4 pathways [15,19-21]. Moreover, p38 MAPK activity has been shown to be regulated by cAMP [26-30]. Considering the above results and the fact that melatonin, via its MT1 receptor, regulates the intracellular concentration of cAMP in breast cancer cells [31], we hypothesize that melatonin plays an inhibitory role in breast cancer cell invasion by 
modulating the activation of the p38 MAPK pathway. Our results demonstrated that melatonin suppresses the in vitro invasive potential of breast cancer cells by altering the phosphorylation of p38 MAPK and the downstream activity of MMP-2 and MMP-9.

\section{Materials and methods}

\section{Chemicals and reagents}

All chemicals and tissue culture reagents were purchased from Sigma-Aldrich (St. Louis, MO, USA). Cell culture medium, Dulbecco's modified eagle medium (DMEM)/F-12 (1:1), RPMI 1640, and fetal bovine serum (FBS) were purchased from Gibco BRL (now part of Invitrogen Corporation, Carlsbad, CA, USA). The FuGENE 6 transfection reagent was purchased from Roche (Indianapolis, IN, USA). SDF-1/CXCL12 was purchased from Research Diagnostics Inc. (now part of Fitzgerald Industries International, Acton, MA, USA).

\section{Cell lines and cell culture}

Eight human breast cancer cell lines were used in these studies. The MDA-MB-231 human breast cancer cell was purchased from American Type Culture Collection (Manassas, VA, USA). The parental MCF-7 cell was obtained from the laboratory of the late William $\mathrm{L}$ McGurie (San Antonio, TX, USA). The MCF-7/6 and MCF-7/AZ (control MCF-7 cell for MCF-7/6) cells were kindly provided by Marc Mareel. The MCF-7/Her2.1 (stably transfected with Her2/neu in pcDNA3.1 vector and overexpresses wild-type Her2/neu) and its control cell MCF-7/vec were generously provided by Frank E Jones (Tulane University, New Orleans, LA, USA). The MCF-7/CXCR4 cell line (stably transfected with CXCR4 in pcDNA3 vector and overexpresses CXCR4) and its control counterpart MCF-7/pcDNA3 were gifts from Matthew E Burow (Tulane University, New Orleans, LA, USA). All cell lines, except MCF-7/6 and MCF-7/AZ, were cultured in RPMI 1640 medium supplemented with 10\% FBS (Gibco BRL), $50 \mathrm{mM}$ minimum essential medium non-essential amino acids, $1 \mathrm{mM}$ sodium pyruvate, $2 \mathrm{mM}$ glutamine, $10 \mathrm{mM}$ basal medium eagle, 100 $\mathrm{mg} / \mathrm{mL}$ streptomycin, and $100 \mathrm{U} / \mathrm{mL}$ penicillin. The MCF-7/6 and MCF-7/AZ cells were cultured in DMEM/F-12 (1:1) with the same supplements described above. These cell lines were routinely maintained at $37^{\circ}$ $\mathrm{C}$ in a humidified atmosphere of $5 \% \mathrm{CO}_{2}$ and $95 \%$ air.

\section{Total RNA extraction and reverse transcriptase-} polymerase chain reaction analysis

Reverse transcriptase-polymerase chain reaction (RTPCR) analysis was performed to confirm the overexpression of MT1 in MT1-transfected cells. Total cellular RNA was isolated using the TRIzol reagent (Invitrogen Corporation) in accordance with the manufacturer's instructions. Reverse transcription was performed on 1 $\mu \mathrm{g}$ of total RNA using Superscript II RNase H- reverse transcriptase (Invitrogen Corporation) and 200 ng random hexadeoxynulceotide primers in $20-\mu \mathrm{L}$ reaction volumes containing $3 \mathrm{mM} \mathrm{MgCl} 2,10 \mathrm{mM}$ DTT, $75 \mathrm{mM}$ $\mathrm{KCl}$, and $0.5 \mathrm{mM} \mathrm{dNTP}$. The polymerase chain reaction (PCR) amplification was conducted using primer sets as previously described [32]. Aliquots of the PCR products were separated on a $1 \%$ agarose gel.

\section{Real-time reverse transcriptase-polymerase chain reaction analysis}

Real-time RT-PCR was performed to determine the mRNA levels of MMP-9 in MCF-7 cells transiently transfected with CAMKK6b. Total cellular RNA was isolated using the PerfectPure RNA Cultured Cell Kit (5 Prime, Gaithersburg, MD, USA) in accordance with the manufacturer's instructions. Reverse transcription was performed on $1 \mu \mathrm{g}$ of total RNA using Superscript II RNase $\mathrm{H}$ - reverse transcriptase (Invitrogen Corporation) and $200 \mathrm{ng}$ random hexadeoxynulceotide primers in 20$\mu \mathrm{L}$ reaction volumes containing $3 \mathrm{mM} \mathrm{MgCl}, 10 \mathrm{mM}$ DTT, $75 \mathrm{mM} \mathrm{KCl}$, and $0.5 \mathrm{mM}$ dNTP. Real-time PCR was carried out in $20 \mu \mathrm{L}$ of PCR mixture containing 10 $\mu \mathrm{L}$ of $2 \times$ iQ SYBR Green Supermix and $1 \mu \mathrm{L}$ of each cDNA sample on an $\mathrm{iCycler} \mathrm{iQ}$ real-time detection system (Bio-Rad Laboratories, Inc., Hercules, CA, USA) in triplicates and recorded in real time and analyzed using the accompanying program (iCycler iQ real-time PCR detection system software, version 3.0A; Bio-Rad Laboratories, Inc.). The level of the $18 \mathrm{~s}$ ribosomal RNA was also determined by real-time RT-PCR in each cDNA sample to normalize the expression of MMP-9. The primers used were as follows: human MMP-9: forward primer, 5'-TGACAGCGACAAGAAGTG-3', and reverse primer, 5'-CAGTGAAGCGGTACATAGG-3'; 18s ribosomal RNA: forward primer, 5'-TTGACGGAA GGGCACCACCAG-3', and reverse primer, 5'-GCACCA CCACCCACGGAATCG-3'. Melt curve analysis was performed at the end of each PCR to confirm the specificity of the PCR product. Threshold cycle $(\mathrm{Ct})$ values of MMP-9 among samples were compared after correction for $18 \mathrm{~s}$ expression. The ratio of MMP-9 versus the corresponding $18 \mathrm{~s}$ of each sample was determined on the basis of the equation MMP-9/18s $=2^{\mathrm{Ct}(18 \mathrm{~s})}-\mathrm{Ct}($ MMP-9) . The ratio of MMP-9/18s was compared among samples, and the fold change of MMP-9 expression was obtained by setting the values from vector-transfected cells to 1 .

\section{Cell proliferation assay}

For melatonin response studies, MCF-7, MCF-7/AZ, MCF-7/6 cells, MCF-7/vec, MCF-7/Her2.1, and MDAMB-231 cells were seeded at a density of $2.0 \times 10^{4}$ cells per well, serum-starved for 24 hours, and treated with 
melatonin $\left(10^{-9} \mathrm{M}\right)$, or diluent $(0.00001 \%$ ethanol), in complete medium supplemented with $10 \%$ FBS. Cells were counted after 6 days of melatonin exposure on a hemacytometer using trypan blue to select for viable cells.

\section{Protein extraction and Western blot analysis}

Cells were harvested and then lysed in a protein extraction buffer containing Tris $(50 \mathrm{mM}, \mathrm{pH} 7.4)$, EDTA $(20 \mathrm{mM})$, $\mathrm{NP}-40$ (0.5\%), $\mathrm{NaCl}(150 \mathrm{mM})$, phenylmethylsulfonyl fluoride $(0.3 \mathrm{mM}), \mathrm{NaF}(1 \mathrm{mM}), \mathrm{NaVO}_{4}(1 \mathrm{mM})$, dithiothreitol $(1 \mathrm{mM})$, aprotinin $(1 \mu \mathrm{g} / \mathrm{mL})$, leupeptine $(1 \mu \mathrm{g} /$ $\mathrm{mL})$, and pepstatin $(1 \mu \mathrm{g} / \mathrm{mL})$. The cell lysates were centrifuged for 10 minutes at $10,000 \mathrm{~g}$ at $4^{\circ} \mathrm{C}$. Protein concentrations of the supernatants were determined using a protein assay kit (Bio-Rad Laboratories, Inc.). Total protein (50 $\mathrm{\mu g}$ per sample) was electrophoretically separated on a $10 \%$ SDS-polyacrylamide gel and electroblotted onto a Hybond membrane. After incubation with 5\% non-fat milk in Trisbuffered saline containing $0.1 \%$ Tween, the immunoblots were probed with antibodies to MT1, Her2/neu (Santa Cruz Biotechnology, Inc., Santa Cruz, CA, USA), CXCR4 (Abcam, Cambridge, MA, USA), phospho-p38 (Thr180/ Tyr182), phospho-p44/42 MAPK (Thr202/Tyr204) (Cell Signaling Technology, Inc., Danvers, MA, USA), MKK6 (Millipore Corporation, Billerica, MA, USA), or phosphoETS1 (Thr38) (Invitrogen Corporation). The same blots were stripped and reprobed with antibodies to $\beta$-actin (Sigma-Aldrich), p38, p44/42 MAPK (Cell Signaling Technology, Inc.), GAPDH (glyceraldehyde-3-phosphate dehydrogenase), or ETS1 (Millipore Corporation), respectively. For MMP-2 and MMP-9 expression studies, the enriched conditioned medium from each treatment group was electrophoretically separated on a 10\% SDS-polyacrylamide gel, and the blots were probed with anti-MMP-2 and antiMMP-9 antibodies (Chemicon, now part of Millipore Corporation).

\section{Transient transfection}

MCF-7/6 or MCF-7/Her2.1 cells were seeded in 150$\mathrm{mm}^{2}$ cell culture flasks at a density of $3.16 \times 10^{6}$ cells per flask in DMEM/F-12 (1:1) medium or RPMI-1640 supplemented with $10 \%$ FBS. After 24-hour serum starvation, cells were then transfected with $7.9 \mu \mathrm{g}$ of pcDNA3.1-MT1 or pcDNA3.1 empty vector or with 7.9 $\mu \mathrm{g}$ of CA-MKK6b (a dominant-positive MKK6b construct provided by Matthew E Burow) or pcDNA3 empty vector, using the FuGENE 6 transfection reagent. Twenty-four hours following transfection, these cells were seeded for matrigel invasion assays.

\section{Matrigel invasion chamber assay}

The invasive potential of breast cancer cells was assessed in vitro in matrigel-coated invasion Chambers (BD BioCoat Matrigel Invasion Chamber; Becton
Dickinson Biosciences, Franklin Lakes, NJ, USA) in accordance with the manufacturer's instructions. Briefly, cells in log phase of growth were serum-starved for 24 hours prior to seeding, detached by brief trypsinization, and resuspended in medium containing the appropriate treatment. The matrigel invasion inserts were rehydrated and prepared as described in the manufacturer's instructions. Cells $\left(5 \times 10^{4}\right.$ cells $/ \mathrm{mL}$ in $0.5 \mathrm{~mL}$ serum-free medium) were added in suspension to the upper chamber, and medium $(0.75 \mathrm{~mL}$, supplemented with $10 \%$ FBS as chemoattractant) containing the same treatment was added to the bottom well. After incubation for 4 or 6 days, the non-invasive cells were removed from the upper surface of the membrane, and the invasive cells on the under surface of the membrane were stained with a Diff-Quick staining kit (Dade Behring, now part of Siemens Healthcare Diagnostics, Deerfield, IL, USA) and counted microscopically at $100 \times$ magnification. Five fields per membrane were randomly selected and counted in each group. The percentage of invasive cells was calculated as the percentage invasion through the matrigel membrane relative to the migration through the control membrane, as described in the manufacturer's instructions. Because Cos and colleagues [3] reported that treatment of MCF-7 cells with melatonin for 6 days reduced cell invasion, we first confirmed their results by incubating the cells for 4 or 6 days (as described above) when examining melatonin's effect on the invasion of MCF-7/6 and MCF-7/Her2.1 cells. These results were confirmed in the more common 2day invasion assays (data not shown). In these assays, the underside of the membrane was pre-coated with fibronectin $(20 \mathrm{ng} / \mathrm{mL}$, as chemoattractant) for 1 hour at $37^{\circ} \mathrm{C}$ after rehydration, and the cells were seeded at a higher density ( 2 to $3 \times 10^{6}$ cells $/ \mathrm{mL}$ ) and incubated for 2 days. As similar results were obtained using these different time frames, we chose to employ the 2-day invasion assays in our subsequent experiments.

\section{Preparation of conditioned medium}

MCF-7/6 or MCF-7/CXCR4 cells were cultured in DMEM/F-12 (1:1) or RPMI-1640 (respectively) supplemented with $10 \%$ FBS until confluency. The cells were washed with phosphate-buffered saline three times and then incubated in serum-free medium containing the appropriate treatments. The conditioned medium was collected, and an equal amount of the medium $(0.5 \mathrm{~mL})$ was concentrated approximately 10 -fold by centrifugation at 14,000 $\mathrm{g}$ using Microcon YM-30 columns (Millipore Corporation). The volume of the concentrated medium was measured, and a normalized volume of it $(15 \mu \mathrm{L})$ was stored at $-70^{\circ} \mathrm{C}$ until used for Western blot analysis or gelatin zymography. 


\section{Gelatin zymography}

The activity of MMP-2 and MMP-9 in the conditioned medium was determined by gelatin zymography. Briefly, the conditioned medium (15 $\mu \mathrm{L}$ per sample) was mixed with an equal volume of $2 \times$ SDS sample buffer (Invitrogen Corporation) and subjected under non-reducing conditions to SDS-polyacrylamide gel polymerized with $1 \mathrm{mg} / \mathrm{mL}$ gelatin. Following electrophoresis, the gels were incubated in a renaturing buffer $(2.5 \%$ Triton X-100) with gentle agitation to remove SDS and then incubated in a developing buffer (50 mM Tris- $\mathrm{HCl}$ buffer, $\mathrm{pH} 7.4$, and $10 \mathrm{mM} \mathrm{CaCl}_{2}$ ) overnight at $37^{\circ} \mathrm{C}$. Gels were then stained with SimplyBlue SafeStain (Invitrogen Corporation) and destained in the Gel-Drying solution (Invitrogen Corporation). Gelatinase activity was visualized as clear bands against the bluestained background. Molecular sizes were determined from mobility using gelatin zymography standards (Chemicon).

\section{Statistical analysis}

Data are represented as the mean \pm the standard error of the mean. The statistical significance at $95 \%$ confidence level was determined by one-way analysis of variance followed by a Student Newman-Keuls post hoc test analysis using the Statview software (SAS Institute, Inc., Cary, NC, USA).

\section{Results}

Characterization of MT1 expression and melatonin responsiveness of a panel of human breast cancer cells with various invasive potentials

Three invasive MCF-7 variants were used in our following studies: the MCF-7/6, MCF-7/Her2.1, and MCF-7/ CXCR4 cell lines. Among these three cell lines, MCF-7/ Her2.1 is highly invasive as compared with parental MCF-7 cells (sixfold elevated invasion); MCF-7/6 and MCF-7/CXCR4 cells are moderately to highly invasive as compared with MCF-7 cells showing changes in invasive capacity by 2.6 - and 4.9 -fold, respectively (Figure 1a). Western blot analysis demonstrated that MT1 is expressed in MCF-7, MCF-7/6, MCF-7/Her2.1, and MCF-7/CXCR4 cells, although MCF-7/6 and MCF-7/ CXCR4 cells exhibit lower levels of MT1 protein than MCF-7 and MCF-7/Her2.1 cells (Figure 1b). In addition, melatonin treatment after 6 days significantly suppressed cell growth (by $30 \%$ to $40 \%$ ) in all cells examined except the ER $\alpha$-negative MDA-MB-231 cells, in which no growth inhibition was observed (Figure 1c).

\section{Phosphorylation of ERK1/2 and p38 MAPKs is} upregulated in human breast cancer cells with elevated expression of the Her2/neu or CXCR4

Expression of the Her2/neu and CXCR4 receptor was examined by Western blot analysis. MCF-7/Her2.1 cells showed markedly enhanced expression of Her2/neu as

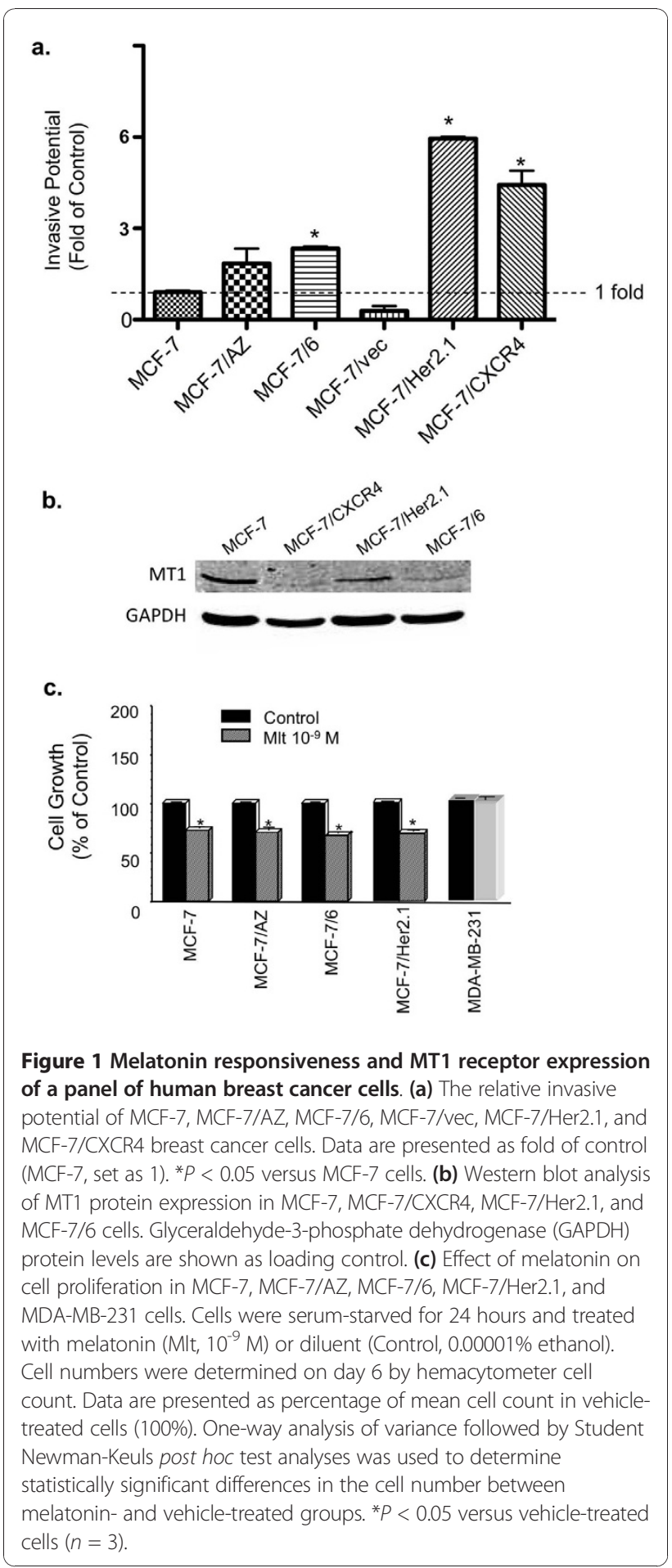

compared with MCF-7/vec cells. Interestingly, Her2/neu expression was also elevated in MCF-7/6 cells as compared with their parental cell line MCF-7/AZ (Figure 2a, top). In addition, CXCR4 expression is elevated by approximately twofold in MCF-7/CXCR4 cells as compared with the MCF-7/pcDNA3 cell line (Figure 2b). 
a.

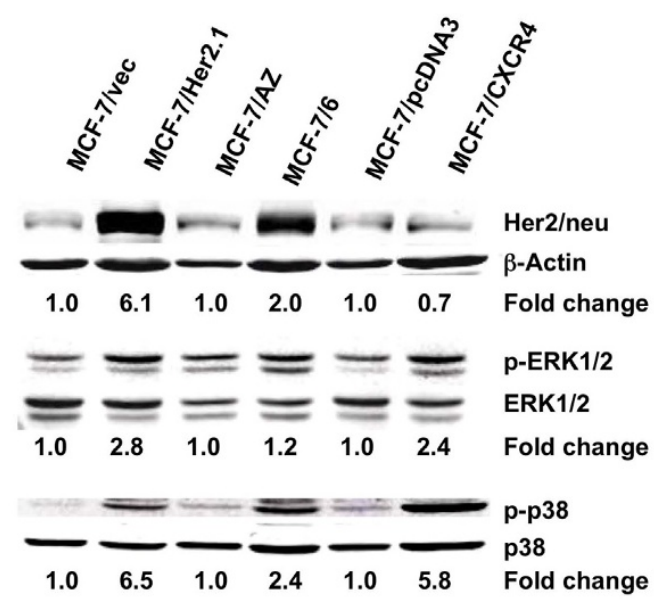

b.

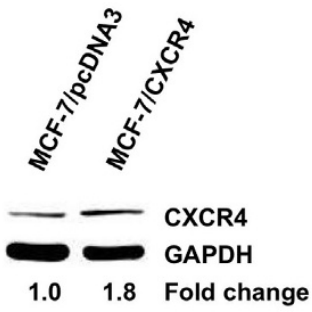

Figure 2 Elevated phosphorylation of ERK $1 / 2$ and p38 MAPK in MCF-7/CXCR4, MCF-7/6, and MCF-7/Her2.1 cells. (a) Western blot analysis of Her2/neu receptor (top), phospho-ERK1/2 (p-ERK1/2) (middle), and phospho-p38 (p-p38) (bottom) in MCF-7/vec, MCF-7/ Her2.1, MCF-7/AZ, MCF-7/6, MCF-7/pCDNA3, and MCF-7/CXCR4 breast cancer cells. The band intensity of Her2/neu, phospho-p38, and phospho-ERK1/2 was normalized to that of $\beta$-actin, total p38, and ERK1/2, respectively, and expressed as fold of control (MCF-7/ vec, MCF-7/AZ, and MCF-7/pcDNA3, set as 1). (b) Western blot analysis of CXCR4 expression in MCF-7/pCDNA3 and MCF-7/CXCR4 cells. Levels of glyceraldehyde-3-phosphate dehydrogenase (GAPDH) are shown as loading control. The band intensity of CXCR4 was normalized to that of GAPDH and expressed as fold of control (MCF-7/pcDNA3, set as 1). ERK1/2, extracellular signal-regulated kinase 1/2; MAPK, mitogen-activated protein kinase.

To further investigate whether Her2/neu overexpression leads to upregulation of downstream MAPKs, we examined the phosphorylation of extracellular signal-regulated kinase 1/2 (ERK1/2) and p38 MAPK by Western blot analysis. Phosphorylation of ERK1/2 was elevated in MCF-7/Her2.1, MCF-7/CXCR4, and MCF-7/6 cells by 2.8-, 2.4-, and 1.2 -fold, respectively, as compared with their respective control cells (Figure 2a, middle). Moreover, phosphorylation of p38 MAPK (Figure 2a, bottom) was markedly elevated in MCF-7/CXCR4 and MCF-7/Her2.1 cells (5.8- and 6.5-fold, respectively) as compared with their respective control cell lines. The MCF-7/6 cells also exhibited increased p38 phosphorylation (2.4-fold) as compared with MCF-7/AZ cells.

\section{Melatonin represses breast cancer cell invasion}

Here, we examined the effect of melatonin on the in vitro invasion of MCF-7/6, MCF-7/Her2.1, and MCF-7/ CXCR4 cells by matrigel invasion chamber assays. Melatonin significantly repressed the invasive potential of all three cell lines. In MCF-7/6 cells, melatonin $\left(10^{-9} \mathrm{M}\right)$ significantly suppressed cell invasion by $32 \%$ by day 4 and $71 \%$ by day 6 (control set as $100 \%$ ). The same concentration of melatonin inhibited the invasion of MCF-7/Her 2.1 cells by $72 \%$ by day 4 and $62 \%$ by day 6 (Figure 3a). In MCF-7/CXCR4 cells, treatment with $10^{-9}$ $\mathrm{M}$ melatonin for 2 days significantly decreased cell invasion (by 66\%) (Figure 3b).

According to previous studies, invasion of CXCR4expressing breast cancer cells is enhanced in response to SDF-1/CXCL12 [33]. To investigate whether melatonin inhibits SDF-1-induced invasion of MCF-7/CXCR4 cells, SDF-1 (300 ng/mL) was added to the bottom well of the matrigel invasion chambers as a chemoattractant. SDF-1 increased the invasive potential of MCF-7/CXCR4 cells by $100 \%$ as compared with the non-stimulated control (no SDF-1 added to the bottom well and diluent-treated, set as $100 \%$ ), and this effect was completely blocked by melatonin administration (Figure $3 \mathrm{~b}$ ).

\section{MT1 receptor mediates melatonin's action on breast cancer cell invasion}

We have previously reported that the MT1 but not the MT2 receptor is expressed in MCF-7 cells [32] and that MT1 mediates melatonin's growth-suppressive effect in MCF-7 cells [32,34,35]. We further examined whether the anti-invasive effect of melatonin is also mediated through the MT1 melatonin receptor. As shown in Figure 3c, melatonin treatment induced a significantly enhanced inhibition of cell invasion (73\%) in cells that are transiently transfected with and that overexpress MT1 as compared with sham-transfected and vector-transfected cells (approximately 40\% inhibition). Moreover, pre-treatment of cells with luzindole, an MT1/MT2 antagonist, for 15 minutes prior to the addition of melatonin completely abrogated melatonin's anti-invasive effect (Figure 3d). These results suggest that the anti-invasive action of melatonin is mediated via the MT1 receptor.

\section{Melatonin suppresses the expression and activity of MMP-2 and MMP-9}

To investigate whether melatonin regulates breast cancer cell invasion by altering the expression of MMPs, particularly MMP-2 and MMP-9, we examined the effect of melatonin on MMP-2 and MMP-9 protein expression in the conditioned medium using MCF-7/6 cells. As determined by Western blot analysis, expression of MMP-9 and MMP-2 was reduced in response to melatonin treatment $\left(10^{-9} \mathrm{M}\right)$ (Figure $\left.4 \mathrm{a}\right)$. 


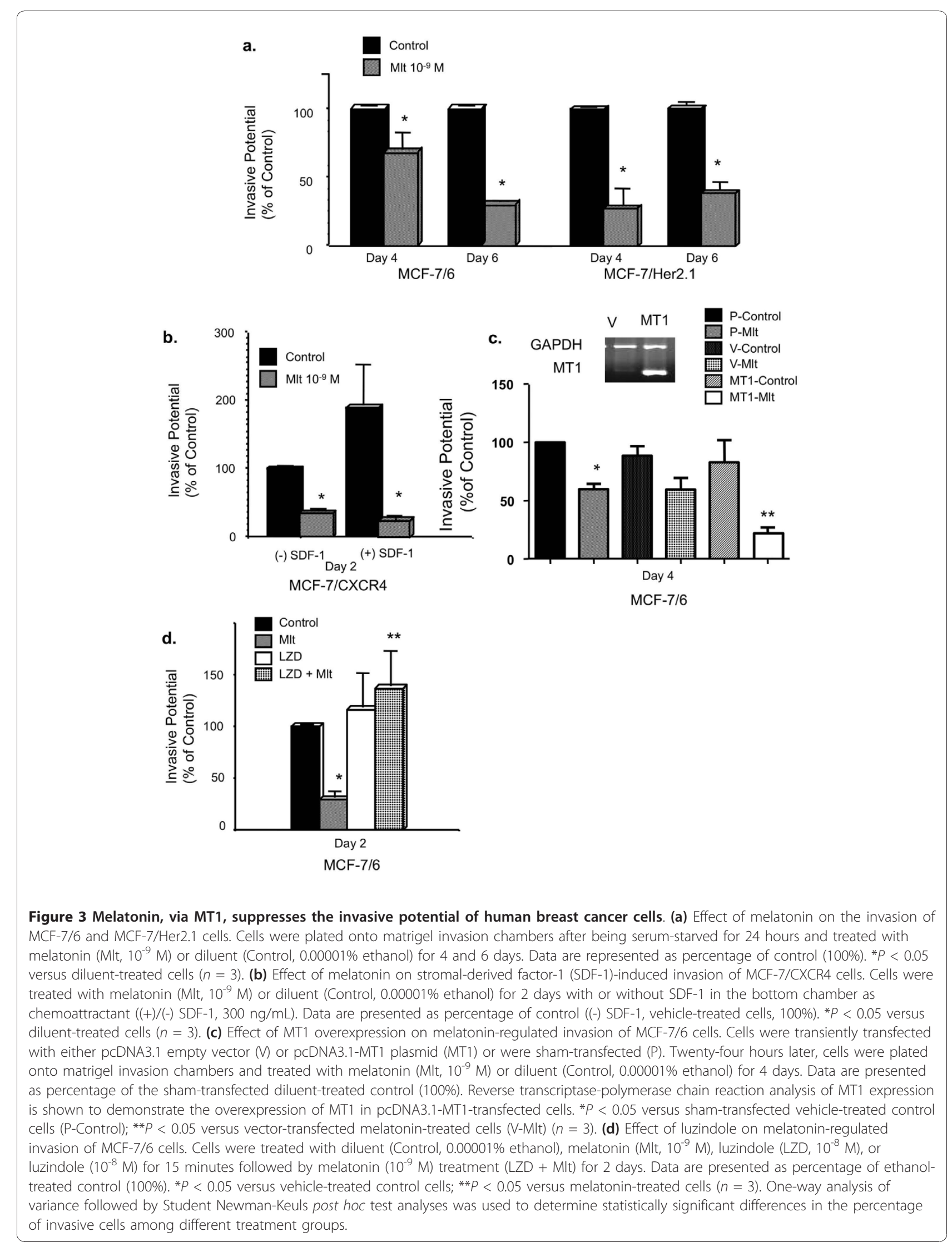


We further examined the effect of melatonin on the activity of MMP-2 and MMP-9 by gelatin zymography. As shown in Figure 4b, a significant (60\%) decrease in the activity of MMP-9 was observed in cells treated with melatonin $\left(10^{-9} \mathrm{M}\right)$ for 48 hours (control set as $100 \%$ ). Similarly, melatonin also induces a significant decrease in MMP-2 activity (70\%) at 48 hours.

Previous studies have shown that one of the mechanisms underlying SDF-1-induced cancer cell invasion is activation of MMP-9 and MMP-2 [33]. Therefore, we further investigated whether melatonin suppresses SDF1-induced MMP-9 and MMP-2 activity. As determined by gelatin zymography, MMP-9 activity was significantly increased (1.5-fold) after administration of SDF-1 (100 $\mathrm{ng} / \mathrm{mL}$ ) for 24 hours as compared with diluent-treated control (set as 1-fold). The SDF-1-mediated induction of MMP-9 activity was completely blocked by simultaneous treatment with melatonin (Figure 4c). However, melatonin did not block SDF-1-induced MMP-2 activity (data not shown). a.

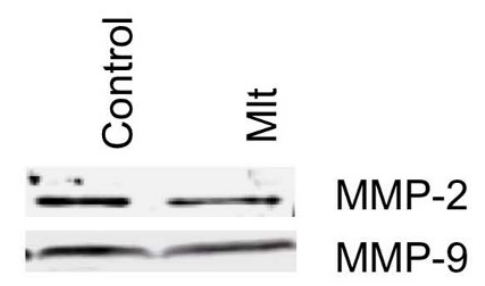

C.

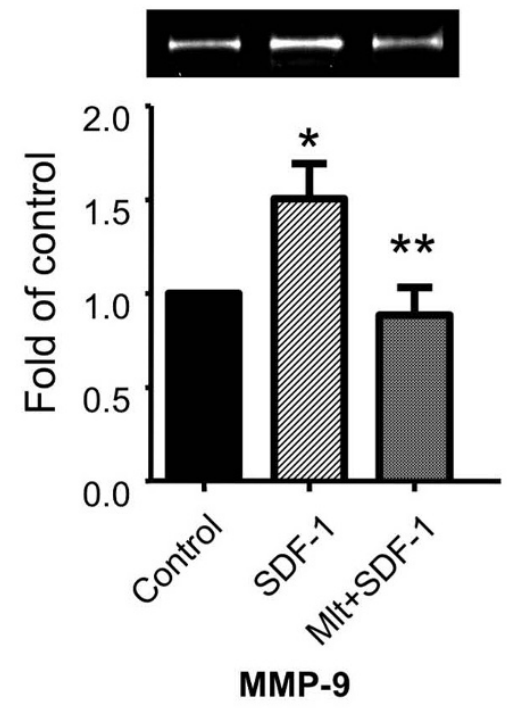

b.

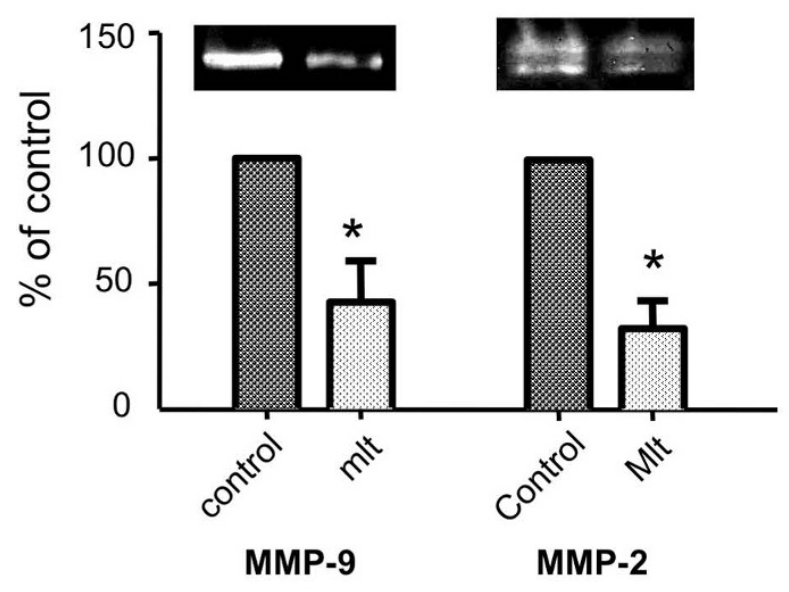

Figure 4 Melatonin suppresses the expression and activity of MMP-2 and MMP-9 in human breast cancer cells. Conditioned medium was collected and concentrated as described in Materials and methods. (a) Melatonin's effect on the protein expression of MMP-2 and MMP-9. MCF-7/6 cells were treated with melatonin (Mlt, 10 $0^{-9} \mathrm{M}$ ) or diluent (Control, $0.00001 \%$ ethanol) for 48 hours. Expression of MMP-2 and MMP-9 in the conditioned medium was analyzed by Western blot analysis using anti-MMP-2 and anti-MMP-9 antibody. (b) The effect of melatonin on the activity of MMP-2 and MMP-9. MCF-7/6 cells were treated with melatonin (Mlt, $10^{-9} \mathrm{M}$ ) or diluent (Control, $0.00001 \%$ ethanol) for 48 hours. The gelatinase activity of MMP-9 and MMP-2 in the conditioned medium was determined by gelatin zymography. The band intensities of MMP-9 and MMP-2, respectively, are presented in the graph as percentages of control (set as 100\%). ${ }^{*} P<0.05$ versus diluent-treated control $(n=4)$. (c) Effect of melatonin on stromal-derived factor-1 (SDF-1)-induced activity of MMP-9 in MCF-7/CXCR4 cells. MCF-7/CXCR4 cells were treated with diluent (control, $0.00001 \%$ ethanol), SDF-1 $(100 \mathrm{ng} / \mathrm{mL})$, or melatonin $\left(10^{-9} \mathrm{M}\right)$ and SDF-1 $(100 \mathrm{ng} / \mathrm{mL})$ simultaneously (Mlt + SDF-1) for 24 hours. The gelatinase activity of MMP-9 in the conditioned medium was determined by gelatin zymography. The band intensity of MMP-9 is presented in the graph as percentage of control (set as 100\%). ${ }^{*} P<0.05$ versus diluent-treated control; ${ }^{* *} P<0.05$ versus SDF-1-treated group $(n=3)$. Figures in $(a-c)$ are representative Western blots or gelatin zymograms of at least three independent studies, respectively. MMP, matrix metalloproteinase. 


\section{Melatonin's anti-invasive actions are mediated through the p38 MAPK pathway}

To investigate whether the MAPKs, ERK1/2 and p38, play a role in melatonin regulation of breast cancer invasion, Western blot analyses were performed to determine whether melatonin regulates the phosphorylation of ERK1/2 and p38 MAPK. Our results demonstrate that melatonin treatment $\left(10^{-9} \mathrm{M}\right)$ significantly suppressed p38 phosphorylation in MCF-7/6 cells (Figure $5 \mathrm{a}$ ) and in MCF-7/Her2.1 cells (data not shown). The melatonin repression of p38 phosphorylation was abrogated by a 45-minute pre-treatment with H89 (10 $\mu \mathrm{M})$, a protein kinase A (PKA) inhibitor, suggesting that the effect of melatonin on p38 phosphorylation is mediated through PKA (Figure 5c). Furthermore, a robust induction of p38 phosphorylation was observed in MCF-7/CXCR4 cells after 2-minute stimulation with SDF-1 (100 ng/mL), which was blocked by a 5-minute pre-treatment with melatonin (Figure 5b). Conversely, melatonin treatment did not affect the phosphorylation of ERK1/2 in MCF-7/6 cells (data not shown), suggesting that the suppressive effect of melatonin on p38 phosphorylation is specific.

We subsequently conducted matrigel invasion chamber assays to determine whether SB230580, a p38 inhibitor, could mimic melatonin's action on the invasion of MCF-7/6 cells. Treatment of MCF-7/6 cells with melatonin $\left(10^{-9} \mathrm{M}\right)$ induced a significant $(50 \%)$ reduction in the invasive potential of MCF-7/6 cells as compared with diluent-treated controls (ethanol, set as 100\%). Similarly, SB230580 significantly inhibited the invasion of MCF-7/6 cells (by 50\%) compared with diluent-treated group (dimethyl sulfoxide) (Figure 5d).

The activity of p38 MAPK is regulated by the upstream kinase, MKK6 [36]. To investigate whether upregulation of p38 activity by transfection with a constitutively active MKK6b DNA construct (CAMKK6b) could reverse melatonin's effect on MCF-7/Her2.1 cell invasion, we conducted invasion assays and phosphorylation analyses of p38 by Western blot analyses. As demonstrated in Figure 5e, p38 phosphorylation was upregulated in CAMKK6b-transfected cells. In vectortransfected cells, melatonin treatment significantly suppressed cell invasion (by 70\%) as compared with ethanol-treated control (set as 100\%). In contrast, melatonin did not have a significant effect on the invasive potential of CAMKK6b-transfected cells (Figure 5e).

\section{CAMKK6b upregulates MMP-9 mRNA expression and ETS1 phosphorylation}

MMP-9 has been shown to be a target gene of the transcription factor ETS1 [37]. There is evidence that p38 can phosphorylate and potentially activate ETS1 [38]. To investigate whether p38 regulates the transcription of MMP-9, real-time RT-PCR analyses were performed to determine the mRNA expression of MMP-9 in MCF7 cells transiently transfected with CAMKK6b. As shown in Figure 6a, MMP-9 mRNA levels were significantly increased in CAMKK6b-transfected cells as compared with vector-transfected cells. This induction of MMP-9 mRNA expression was accompanied by an increase in the phosphorylation of ETS1 as determined by Western blot analyses (Figure 6b).

\section{Discussion}

To define the role of melatonin in breast cancer cell invasion and metastasis, we used three invasive breast cancer cell clones that were derived from the parental MCF-7 cells - the MCF-7/6, MCF-7/Her2.1, and MCF$7 / \mathrm{CXCR} 4$ cells - instead of using the poorly invasive MCF-7 breast cancer cells. These three cell clones were selected because they are highly invasive and metastatic as compared with the parental MCF-7 cells while still retaining many characteristics of the parental MCF-7 cells.

As shown in Figure 1, MT1 is expressed at the protein level in all three cell lines, with MCF-7/Her2.1 cells exhibiting highest level of MT1. In addition, both MCF$7 / 6$ and MCF-7/Her2.1 cells are responsive to melatonin's growth-suppressive effect, with melatonin $\left(10^{-9} \mathrm{M}\right)$ showing equal effectiveness in suppressing the growth of these cells as it does in parental MCF-7 cells (Figure 1). When it comes to the ability to invade and metastasize, MCF-7/6, MCF-7/Her2.1, and MCF-7/CXCR4 cells all exhibited elevated invasive potential as compared with the parental MCF-7 cells.

The enhanced invasive potential in MCF-7/Her2.1 and MCF-7/6 cells, respectively, may be a direct result of Her2/neu overexpression. According to previous reports, overexpression of Her2/neu and constitutive activation of the Her2/neu signaling pathway can constitutively activate MAPK [11] while promoting breast cancer cell invasion and metastasis [12-14]. As expected, expression of Her2/neu is markedly upregulated in MCF-7/Her2.1 cells that have been transfected with the wild-type Her2/neu. Interestingly, Her2/neu is also overexpressed in MCF-7/6 cells that have been selected for metastatic potential by serial passaging in nude mice. These data suggest that upregulation of the Her2/neu pathway may be one of the early events in the progression toward invasiveness.

Although the precise mechanisms by which the Her2/ neu pathway regulates breast cancer invasion and metastasis are not yet fully understood, it has been suggested that multiple signaling pathways, including ERK1/2 and p38, act as the downstream effectors to promote the invasive potential of these breast cancer cells [15]. Therefore, it is possible that MCF-7/Her2.1 and MCF-7/ 
a.

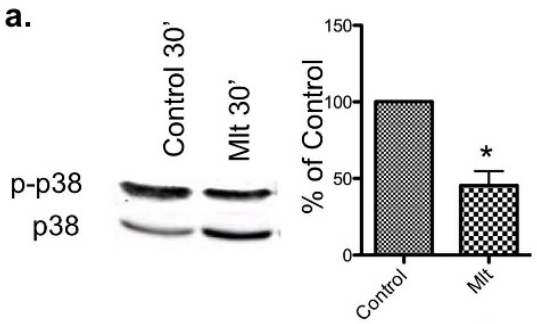

c.
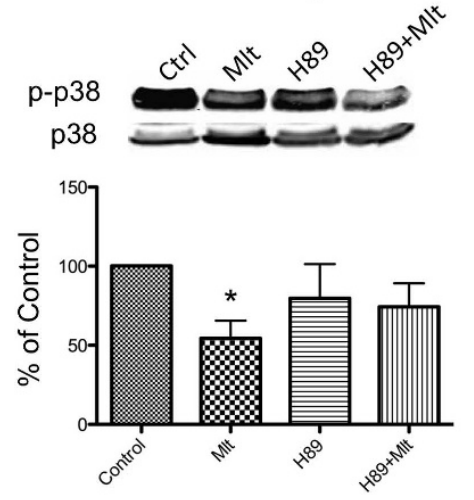

e.

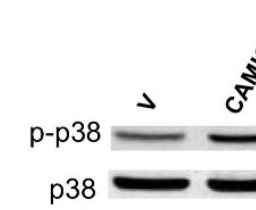

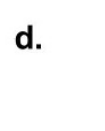

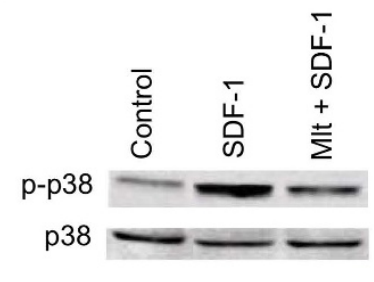

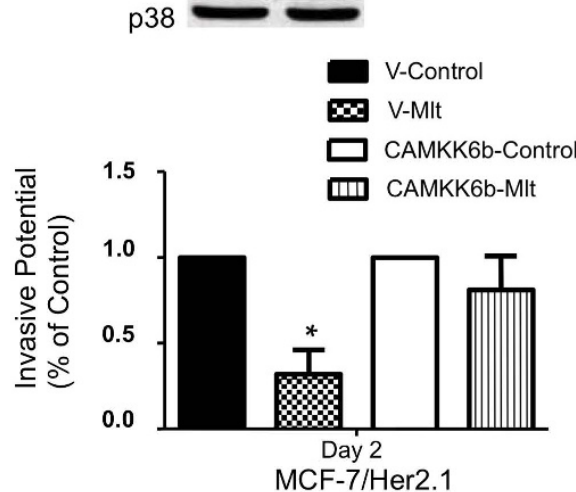

ETOH

$\square$ Mit

$\square$ DMSO

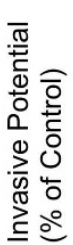

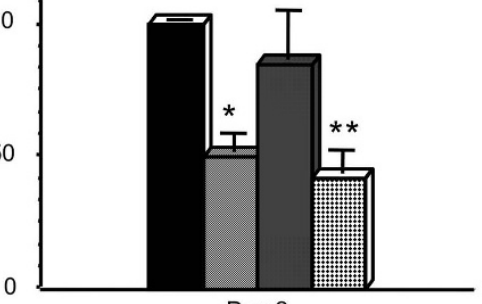

Day 2

MCF-7/6

Figure 5 The anti-invasive effects of melatonin are mediated through the p38 MAPK signaling pathway. (a) The effect of melatonin on the phosphorylation of p38 MAPK. MCF-7/6 cells were serum-starved for 24 hours and treated with diluent (Control, $0.00001 \%$ ethanol) or melatonin (Mlt, 10-9 M) for 30 minutes in fresh medium supplemented with 10\% fetal bovine serum. Expression of phospho-p38 (p-p38) and total p38 (p38) was analyzed by Western blot analysis. (b) The effect of melatonin on stromal-derived factor-1 (SDF-1)-induced p38 phosphorylation. MCF-7/CXCR4 cells were serum-starved for 48 hours and pre-treated with melatonin $\left(10^{-9} \mathrm{M}\right)$ or diluent $(0.00001 \%$ ethanol) for 5 minutes followed by SDF-1 (100 ng/mL) stimulation for 2 minutes (Mlt + SDF-1). (c) The effect of H89 on melatonin regulation of p38 phosphorylation. MCF-7/6 cells were serum-starved for 24 hours and pre-treated with H89 (10 $\mu \mathrm{M})$ for 45 minutes followed by a 30-minute treatment with melatonin $\left(10^{-9} \mathrm{M}\right)$. Figures in $(\mathrm{a}-\mathrm{c})$ are representative Western blots from three independent studies, respectively. In (a) and (c), the band intensity of phospho-p38 was normalized to that of total p38 and expressed in the graph as percentage of control (set as 100\%). ${ }^{*} P<0.05$ versus diluent-treated control $(n=3)$. (d) The effect of SB230580 on the invasive potential of MCF-7/6 breast cancer cells. MCF-7/6 cells were plated onto matrigel invasion chambers after 24-hour serum starvation and incubated in the medium containing diluent (ETOH, $0.00001 \%$ ethanol; dimethyl sulfoxide, or DMSO), melatonin (Mlt, 10-9 M), or SB230580 (20 $\mu \mathrm{M})$. Data are presented as percentage of ethanol-treated control (100\%). ${ }^{*} P<0.05$ versus ethanol-treated control cells. ${ }^{* *} P<0.05$ versus DMSO-treated control cells. (e) Effect of CAMKK6b on melatonin's antiinvasive action. MCF-7/Her2.1 cells were transiently transfected with empty vector (V) or CAMKK6b plasmid for 24 hours, plated onto matrigel invasion chambers, and treated with diluent (Control, $0.00001 \%$ ethanol) or melatonin ( $\mathrm{Mlt}, 10^{-9} \mathrm{M}$ ) for 2 days. Data are presented as percentage of vector-transfected diluent-treated control (100\%). ${ }^{*} P<0.05$ versus vehicle-treated control cells. Phosphorylation of p38 MAPK (p-p38) in vector- and CAMKK6b-transfected cells was analyzed by Western blot analysis. Expression of total p38 (p38) was used as loading control. MAPK, mitogen-activated protein kinase. 


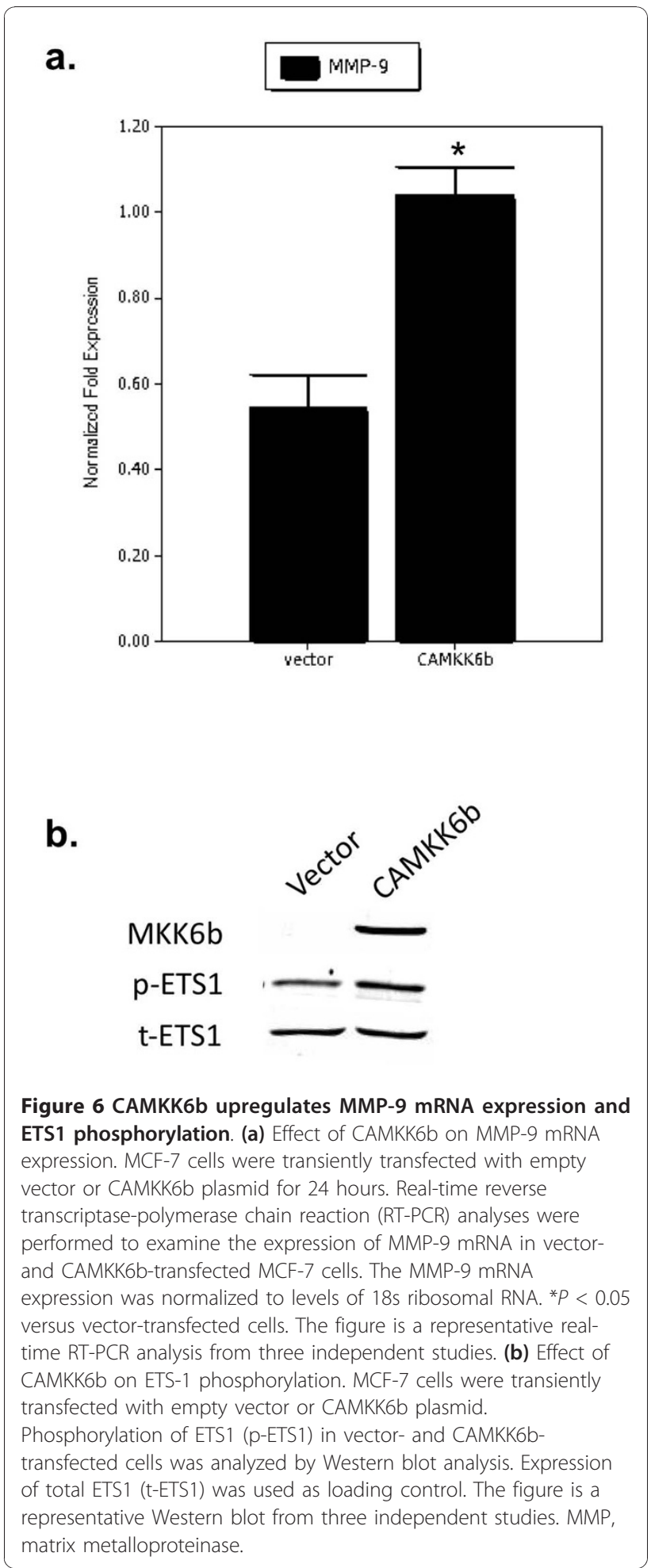

6 cells acquire their invasive capacities through Her2/ neu-induced constitutive activation of ERK $1 / 2$ and p38 MAPK. Recent studies have revealed that the chemokine receptor CXCR4 also plays a critical role in the regulation of breast cancer cell invasion and metastasis [16-18].
The molecular mechanisms underlying the action of CXCR4 on breast cancer cell invasion are currently under intense investigation. Given that activation of CXCR4 leads to activation of multiple signaling pathways, including ERK1/2 and p38, in several cell types [19-21], MCF-7/CXCR4 cells may acquire their invasiveness and metastatic potential through CXCR4-mediated upregulation of the ERK1/2 and p38 MAPK signaling pathways.

To define the role of melatonin in breast cancer cell invasion, the effects of melatonin on breast cancer cell invasion were tested on MCF-7/6, MCF-7/Her2.1, and MCF-7/CXCR4 cells by in vitro matrigel invasion chamber assays. In agreement with the data reported by Cos and colleagues [3], we have demonstrated that melatonin, at physiological concentrations $\left(10^{-9} \mathrm{M}\right)$, significantly inhibits the invasion of MCF-7/6, MCF-7/Her2.1, and MCF-7/CXCR4 breast cancer cells. Furthermore, melatonin blocked the SDF-1/CXCL12-induced invasive potential of MCF-7/CXCR4 cells. Melatonin's anti-invasive action is also reflected by its suppressive effects on the expression of MMP-2 and MMP-9, two major MMPs mediating the degradation of the extracellular matrix. Several reports have indicated that melatonin regulates the activity of MMP-9 during protection against ethanolinduced gastric ulcer and endometriosis $[39,40]$. In our study, melatonin treatment not only reduces the protein expression but also represses the enzymatic activity of MMP-2 and MMP-9. These results suggest that melatonin's anti-invasive action is mediated, at least in part, by diminishing the ability of breast cancer cells to degrade the components of extracellular matrix by modulating MMP-2 and MMP-9 expression and activity. Moreover, previous studies have shown that the activities of MMPs are regulated by a group of endogenous molecules, namely, the tissue inhibitors of matrix metalloproteinase (TIMPs) [41]. According to our unpublished data from cDNA microarray analysis, TIMP-3 expression is upregulated in melatonin-treated MCF-7 cells overexpressing the MT1 receptor, suggesting that TIMP-3 may be another target of melatonin's anti-invasive action.

To delineate the signaling pathway(s) used by melatonin to affect the invasive capacity of breast cancer cells, we first investigated whether melatonin's anti-invasive action is an MT1 receptor-mediated event. We have previously reported that the MT1 but not the MT2 receptor is expressed in MCF-7 cells [32] and that MT1 mediates melatonin's growth-suppressive effect in MCF7 cells $[32,34,35]$. It appears that MT1 is also involved melatonin's anti-invasive actions. As demonstrated in our studies, enhanced MT1 expression potentiated melatonin-mediated inhibition of cell invasion in MCF-7/6 cells. In contrast, this inhibitory effect was abolished by pre-treatment of the cells with luzindole, an MT1/MT2 
antagonist. The above data suggest that melatonin's anti-invasive action is mediated, at least in part, through the G-protein-coupled MT1 receptor.

A well-established key intracellular signaling pathway downstream of the MT1 receptor is the cAMP/PKA pathway. As we previously reported, the MT1 receptor, by coupling to $G_{i}$ proteins upon melatonin binding, blocks the accumulation of cAMP and potentially inhibits the activity of PKA in MCF-7 cell [31]. Considering that the cAMP/ PKA pathway cross-talks with diverse signaling pathways, including the ERK1/2 and p38 MAPK, and drawing inspiration from our observation that constitutive activation of ERK1/2 and p38 MAPK appears to be the driving force to promote the invasion of MCF-7/6, MCF-7/ CXCR4, and MCF-7/Her2.1 cells, we hypothesized that melatonin inhibits the invasion of these cells by interacting with the ERK1/2 and p38 MAPK pathways.
Melatonin regulation of MAPKs has been observed in several cell types, including the COS-7 cell and brain tissue, where melatonin has been reported to increase the phosphorylation of ERK1/2 and JNK (c-Jun N-terminus kinase) [42,43]. In human adult mesenchymal stem cells, the phosphorylation of MEK $1 / 2$ and ERK1/2 is increased by acute melatonin exposure but is inhibited by the longterm melatonin administration [44]. However, our studies show that the anti-invasive action of melatonin is mediated through the 338 MAPK pathway and not the ERK1/2 pathway since melatonin treatment $\left(10^{-9} \mathrm{M}\right)$ repressed p38 phosphorylation in both MCF-7/6 (Figure 5a) and MCF-7/Her2.1 (data not shown) breast cancer cells but had no effect on ERK1/2 phosphorylation (data not shown). Furthermore, the p38 inhibitor, SB230580, mimicked melatonin's effect on cell invasion, significantly reducing the invasive potential of the MCF-7/6 cells

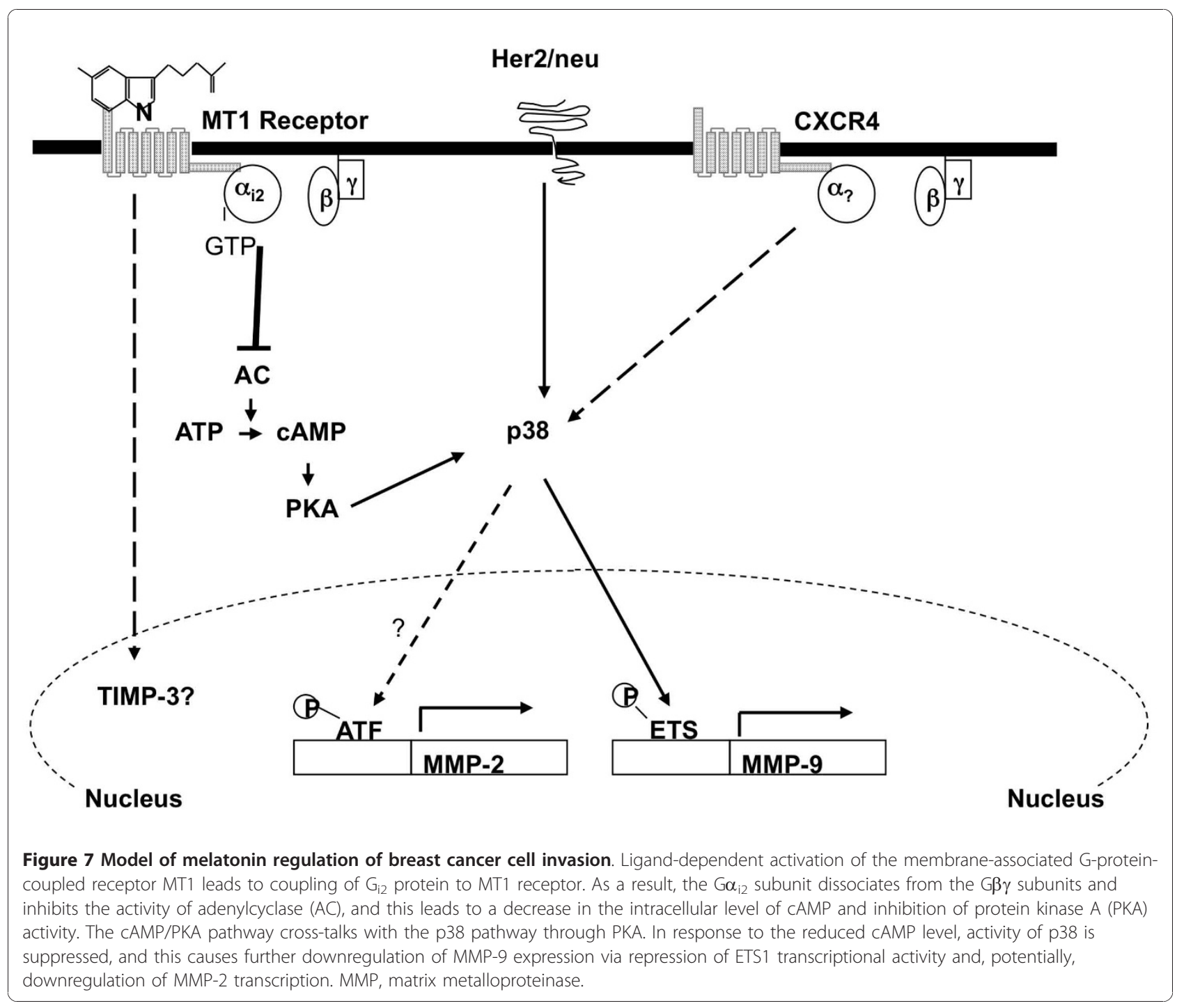


(Figure 5d), while expression of the constitutively active MKK6b blocked melatonin's effect on MCF-7/Her2.1 cell invasion (Figure 5e).

Contrary to what we had expected, expression of CAMKK6b did not significantly induce the invasive potential of MCF-7/Her2.1 cells. This may be due to the hyperactivation of p38 MAPK in these Her2/neu-overexpressing cells (6.5-fold elevated phosphorylation compared with control cell line), which has reached a maximum for its stimulatory effect on cell invasion such that further elevation of p38 activity beyond the maximum does not necessarily lead to further increase in the invasive potential of these already highly invasive breast cancer cells.

Several lines of evidence suggest that p38 MAPK regulates the expression of MMP-9 $[25,45]$. We have shown that expression of CAMKK6b leads to increased MMP-9 mRNA expression and elevated ETS1 phosphorylation in MCF-7 cells (Figure 6). Given that MMP-9 is an ETS1 target gene [37], these results suggest that the MKK6/p38 pathway may regulate MMP-9 transcription through phosphorylation and potentially activation of ETS1.

In summary, the above data suggest that melatonin, via its MT1 receptor, plays an inhibitory role in breast cancer cell invasion, possibly by specifically downregulating the p38 MAPK signaling pathway. Although the precise mechanism or mechanisms underlying melatonin's action on p38 MAPK remain unknown, one possibility is that melatonin regulation of $\mathrm{p} 38$ phosphorylation is mediated through $G_{i}$ protein-induced changes in cAMP level and PKA activity since melatonin's effect on p38 phosphorylation is attenuated by PKA inhibitor H89 (Figure 5c).

In recent years, the p38 MAPK has emerged as a key signaling molecule in the regulation of cancer invasion and metastasis by modulating the expression and activity of molecules governing the degradation of extracellular matrix (that is, urokinase plasminogen activator, MMP-2, and MMP-9) [22-25,45]. Our studies show that phosphorylation of p38 MAPK, but not ERK1/2, is dramatically elevated in both Her2/neu-overexpressing (MCF7/6 and MCF-7/Her2.1) and CXCR4-overexpressing (MCF-7/ CXCR4) cells. These data indicate that, although MCF-7/ 6, MCF-7/Her2.1, and MCF-7/CXCR4 cells acquire their malignant phenotypes through different approaches, constitutive activation of p38 MAPK may be a common mechanism driving the transition of these cells from the poorly/non-invasive phenotype to an invasive phenotype (Figure 7). By inhibiting p38 phosphorylation, melatonin has emerged as a promising anti-invasion factor that may be useful in future cancer therapeutics in prevention not only of breast cancer [46] but also of the 'non-invasive-toinvasive' transition. In addition, cancer metastasis is a multi-step event. Although our studies have clearly demonstrated that melatonin significantly inhibits breast cancer cell invasion in vitro, it is critical to further define the role of melatonin in regulating breast cancer metastasis in vivo to evaluate the clinical significance of melatonin's anti-invasive effect.

\section{Conclusions}

In the present studies, we investigated the role of melatonin in the regulation of breast cancer cell invasion. Our results demonstrated that melatonin, via its MT1 receptor, plays an inhibitory role in breast cancer cell invasion, possibly by specifically downregulating the p38 MAPK signaling pathway, and the downstream activity of MMP-2 and MMP-9.

\section{Abbreviations}

CT: threshold cycle; DMEM: Dulbecco's modified eagle medium; ERo: estrogen receptor-alpha; ERK1/2: extracellular signal-regulated kinase 1/2; FBS: fetal bovine serum; MAPK: mitogen-activated protein kinase; MMP: matrix metalloproteinase; PCR: polymerase chain reaction; PKA: protein kinase A; RT-PCR: reverse transcriptase-polymerase chain reaction; SDF-1: stromal-derived factor-1; TIMP: tissue inhibitor of matrix metalloproteinase.

\section{Acknowledgements}

This article was supported by National Institutes of Health/National Cancer Institute grant 5R01 CA 54152-14. We thank Marc Mareel for kindly providing the MCF-7/6 human breast cancer cells.

\section{Author details}

${ }^{1}$ Department of Structural and Cellular Biology, Tulane University School of Medicine, 1430 Tulane Avenue, New Orleans, LA 70112, USA. ${ }^{2}$ Tulane Cancer Center, Tulane University School of Medicine, 1430 Tulane Avenue, New Orleans, LA 70112, USA. ${ }^{3}$ Department of Cell and Molecular Biology, Tulane University, 2000 Percival Stern, New Orleans, LA 70118, USA. ${ }^{4}$ Department of Medicine, Tulane University School of Medicine, 1430 Tulane Avenue, New Orleans, LA 70112, USA.

\section{Authors' contributions}

LM participated in the overall study design, carried out the molecular studies, and drafted the manuscript. LY carried out the RT-PCR analysis. LMS performed some of the Western blot analyses. FEJ and MEB critically revised the manuscript. SMH conceived the study and participated in its design and coordination and helped to draft the manuscript. All authors read and approved the final manuscript.

\section{Competing interests}

The authors declare that they have no competing interests.

Received: 15 June 2010 Revised: 16 October 2010

Accepted: 17 December 2010 Published: 17 December 2010

\section{References}

1. Barni S, Lissoni P, Crispino S, Cattaneo G, Rovelli F, Fumagalli G, Tancini G: Neuroimmunomodulation in cancer patients: correlations between melatonin and beta-endorphin blood levels and T helper/suppressor ratio. Int J Biol Markers 1988, 3:82-86.

2. Lissoni P, Bastone A, Sala R, Mauri R, Rovelli F, Viviani S, Bajetta E, Esposti D, Esposti G, di Bella L, Fraschini F: The clinical significance of melatonin serum determination in oncological patients and its correlation with GH and PRL blood levels. Eur J Cancer Clin Oncol 1987, 23:949-957.

3. Cos S, Fernandez R, Guezmes A, Sanchez-Barcelo EJ: Influence of melatonin on invasive and metastatic properties of MCF-7 human breast cancer cells. Cancer Res 1998, 58:4383-4390.

4. Anisimov VN, Alimova IN, Baturin DA, Popovich IG, Zabezhinski MA Manton KG, Semenchenko AV, Yashin Al: The effect of melatonin treatment regimen on mammary adenocarcinoma development in HER2/neu transgenic mice. Int J Cancer 2003, 103:300-305. 
5. Baturin DA, Alimova IN, Anisimov VN, Popovich IG, Zabezhinski MA, Provinciali M, Mancini R, Franceschi C: The effect of light regimen and melatonin on the development of spontaneous mammary tumors in HER-2/neu transgenic mice is related to a downregulation of HER-2/neu gene expression. Neuro Endocrinol Lett 2001, 22:441-447.

6. Leon-Blanco MM, Guerrero JM, Reiter RJ, Calvo JR, Pozo D: Melatonin inhibits telomerase activity in the MCF-7 tumor cell line both in vivo an in vitro. J Pineal Res 2003, 35:204-211.

7. Bracke ME, Van Larebeke NA, Vyncke BM, Mareel MM: Retinoic acid modulates both invasion and plasma membrane ruffling of MCF-7 human mammary carcinoma cells in vitro. Br J Cancer 1991, 63:867-872.

8. Correc $P$, Fondaneche $M-C$, Bracke $M$, Burtin P: The presence of plasmin receptors on three mammary carcinoma MCF-7 sublines. Int J Cancer $1990,46: 745-750$.

9. Holbro T, Civenni G, Hynes NE: The ErbB receptors and their role in cancer progression. Exp Cell Res 2003, 284:99-110.

10. Berger MS, Locher GW, Saurer S, Gullick WJ, Waterfield MD, Groner B, Hynes NE: Correlation of c-erbB-2 gene amplification and protein expression in human breast carcinoma with nodal status and nuclear grading. Cancer Res 1988, 48:1238-1243.

11. Oh AS, Lorant LA, Holloway JN, Miller DL, Kern FG, El-Ashry D: Hyperactivation of MAPK induces loss of ERa expression in breast cancer cells. Mol Endocrinol 2001, 15:1344-1359.

12. Ignatoski KM, Maehama T, Markwart SM, Dixon JE, Livant DL, Ethier SP. ERBB-2 overexpression confers PI 3' kinase-dependent invasion capacity on human mammary epithelial cells. Br J Cancer 2000, 82:666-674.

13. Tan M, Yao J, Yu D: Overexpression of the c-erbB-2 gene enhanced intrinsic metastasis potential in human breast cancer cells without increasing their transformation abilities. Cancer Res 1997, 57:1199-1205.

14. Moody SE, Sarkisian CJ, Hahn KT, Gunther EJ, Pickup S, Dugan KD, Innocent N, Cardiff RD, Schnall MD, Chodosh LA: Conditional activation of $\mathrm{Neu}$ in the mammary epithelium of transgenic mice results in reversible pulmonary metastasis. Cancer Cell 2002, 2:451-461

15. Ke Z, Lin H, Fan Z, Cai TQ, Kaplan RA, Ma C, Bower KA, Shi X, Luo J: MMP-2 mediates ethanol-induced invasion of mammary epithelial cells overexpressing ErbB2. Int J Cancer 2006, 119:8-16.

16. Müller A, Homey B, Soto H, Ge N, Catron D, Buchanan ME, McClanahan T, Murphy E, Yuan W, Wagner SN, Barrera JL, Mohar A, Verástegui E, Zlotnik A: Involvement of chemokine receptors in breast cancer metastasis. Nature 2001, 410:50-56

17. Liang ZX, Yoon YH, Votaw H, Goodman MM, Williams L, Shim H: Silencing of CXCR4 blocks breast cancer metastasis. Cancer Res 2005, 65:967-971.

18. Chen Y, Stamatoyannopoulos G, Song CZ: Down-regulation of CXCR4 by inducible small interfering RNA inhibits breast cancer cell invasion in vitro. Cancer Res 2003, 63:4801-4804.

19. Bendall LJ, Baraz R, Juarez J, She W, Bradstock KF: Defective p38 mitogenactivated protein kinase signaling impairs chemotaxic but not proliferative responses to stromal-derived factor-1alpha in acute lymphoblastic leukemia. Cancer Res 2005, 65:3290-3298.

20. Rousseau S, Dolado I, Beardmore V, Shpiro N, Marquez R, Nebreda AR, Arthur JS, Case LM, Tessier-Lavigne M, Gaestel M, Cuenda A, Cohen P. CXCL12 and C5a trigger cell migration via a PAK1/2-p38alpha MAPKMAPKAP-K2-HSP27 pathway. Cell Signal 2006, 18:1897-1905.

21. Robledo MM, Bartolome RA, Longo N, Rodríguez-Frade JM, Mellado M, Longo I, van Muijen GN, Sánchez-Mateos P, Teixidó J: Expression of functional chemokine receptors CXCR3 and CXCR4 on human melanoma cells. J Biol Chem 2001, 276:45098-45105.

22. Han Q, Leng J, Bian D, Mahanivong C, Carpenter KA, Pan ZK, Han J, Huang S: Rac1-MKK3-p38-MAPKAPK2 pathway promotes urokinase plasminogen activator mRNA stability in invasive breast cancer cell. $J$ Biol Chem 2002, 277:48379-48385.

23. Kim MS, Lee EJ, Kim HR, Moon A: p38 kinase is a key signaling molecule for H-Ras-induced cell motility and invasive phenotype in human breast epithelial cells. Cancer Res 2003, 63:5454-5461

24. Cardone RA, Bagorda A, Bellizzi A, Busco G, Guerra L, Paradiso A, Casavola V, Zaccolo M, Reshkin SJ: Protein kinase A gating of a pseudopodial-located RhoA/ROCK/p38/NHE1 signal module regulates invasion in breast cancer cell lines. Mol Biol Cell 2005, 16:3117-3127.

25. Shin I, Kim S, Song H, Kim HR, Moon A: H-Ras-specific activation of RacMKK3/6-p38 pathway: its critical role in invasion and migration of breast epithelial cells. J Biol Chem 2005, 280:14675-14683.
26. Delghandi MP, Johannessen M, Moens U: The cAMP signaling pathway activates CREB through PKA, p38 and MSK1 in NIH 3 T3 cells. Cell Signal 2005, 17:1343-1351.

27. Suzuki A, Palmer G, Bonjour JP, Caverzasio J: Regulation of alkaline phoaphatase activity of p38 MAP kinase in response to activation of Gi protein-coupled receptors by epinephrine in osteoblast-like cells. Endocrinology 1999, 140:3177-3182.

28. Husain S, Abdel-Latif AA: Endothelin-1 activates p38 mitogen-activated protein kinase and cytosolic phospholiase A2 in cat iris sphincter smooth muscle cells. Biochem J 1999, 342:87-96.

29. Komatsu J, Yamano S, Kuwahara A, Tokumura A, Irahara M: The signaling pathways linking to lysophosphatidic aid-promoted meiotic maturation in mice. Life Sci 2006, 79:506-511.

30. Zheng M, Zhang SJ, Zhu WZ, Ziman B, Kobilka BK, Xiao RP: Beta 2adrenergic receptor-induced p38 MAPK activation is mediated by protein kinase $\mathrm{A}$ rather than by $\mathrm{Gi}$ or Gbeta gamma in a adult mouse cardiomyocytes. J Biol Chem 2000, 275:40635-40640.

31. Kiefer TL, Yuan L, Ram PT, Hill SM: Melatonin inhibits estrogen receptor transactivation and CAMP levels in MCF-7 human breast cancer cells. Breast Cancer Res Treat 2002, 71:37-45.

32. Ram PT, Dai J, Yuan L, Dong C, Kiefer TL, Lai L, Hill SM: Involvement of the $\mathrm{mt} 1$ melatonin receptor in human breast cancer. Cancer Lett 2002, 179:141-150.

33. Fernandis AZ, Prasad A, Band H, Klosel R, Ganju RK: Regulation of CXCR4mediated chemotaxis and chemoinvasion of breast cancer cells. Oncogene 2004, 23:157-167.

34. Yuan L, Collins AR, Dai J, Dubocovich ML, Hill SM: MT1 melatonin receptor overexpression enhances the growth suppressive effect of melatonin in human breast cancer cells. Mol Cell Endocrinol 2002, 192:147-156.

35. Collins A, Yuan L, Kiefer TL, Cheng Q, Lai L, Hill SM: Overexpression of the MT1 melatonin receptor in MCF-7 human breast cancer cells inhibits mammary tumor formation in nude mice. Cancer Lett 2003, 189:49-57.

36. Cuenda A, Rousseau S: p38 MAP-kinases pathway regulation, function and role in human diseases. Biochim Biophys Acta 2007, 1773:1358-1375.

37. Dittmer J: The biology of the Ets1 proto-oncogene. Mol Cancer 2003, 2:29.

38. Paumelle $R$, Tulasne D, Kherrouche Z, Plaza S, Leroy C, Reveneau S, Vandenbunder B, Fafeur V: Hepatocyte growth factor/scatter factor activates the ETS1 transcription factor by a RAS-RAF-MEK-ERK signaling pathway. Oncogene 2002, 21:2309-2319.

39. Swarnakar S, Mishra A, Ganguly K, Sharma AV: Matrix metalloproteinase-9 activity and expression is reduced by melatonin during prevention of ethanol-induced gastric ulcer in mice. J Pineal Res 2007, 43:56-64.

40. Paul S, Sharma AV, Mahapatra PD, Bhattacharya P, Reiter RJ, Swarnakar S: Role of melatonin in regulating matrix metalloproteinase- 9 via tissue inhibitors of metalloproteinase- 1 during protection against endometriosis. J Pineal Res 2008, 44:439-449.

41. Woessner JF, Nagase H: Matrix Metalloproteinases and TIMPs (Protein Profile) New York, NY: Oxford University Press; 2000

42. Chan AS, Lai FP, Lo RK, Voyno-Yasenetskaya TA, Stanbridge EJ, Wong YH: Melatonin $\mathrm{mt} 1$ and $\mathrm{MT} 2$ receptors stimulate c-Jun N-terminal kinase via pertussis toxin-sensitive and -insensitive G proteins. Cell Signal 2002, 14:249-257.

43. Kilic U, Kilic E, Reiter RJ, Bassetti CL, Hermann DM: Signal transduction pathways involved in melatonin-induced neuroprotection after focal cerebral ischemic in mice. J Pineal Res 2005, 38:67-71.

44. Radio NM, Doctor JS, Witt-Enderby PA: Melatonin enhances alkaline phoshoatase activity in differentiating human adult mesenchymal stem cells grown in osteogenic medium via MT2 melatonin receptors and the MEK/ERK (1/2) signaling cascade. J Pineal Res 2006, 40:332-342.

45. Loesch M, Zhi HY, Hou SW, Qi XM, Li RS, Basir Z, Iftner T, Cuenda A, Chen G: p38gamma MAPK cooperates with c-Jun in trans-activating matrix metalloproteinase 9. J Biol Chem 2010, 285:15149-15158.

46. Teplitzky SR, Kiefer TL, Cheng Q, Dwivedi PD, Moroz K, Myers L, Anderson MB, Collins A, Dai J, Yuan L, Spriggs LL, Blask DE, Hill SM: Chemoprevention of NMU-induced rat mammary carcinoma with the combination of melatonin and 9-cis-retinoic acid. Cancer Lett 2001, 168:155-163.

doi:10.1186/bcr2794

Cite this article as: Mao et al:: Inhibition of breast cancer cell invasion by melatonin is mediated through regulation of the p38 mitogenactivated protein kinase signaling pathway. Breast Cancer Research 2010 12:R107. 